\title{
Tungiasis under dermoscopy: in vivo and ex vivo examination of the cutaneous infestation due to Tunga penetrans ${ }^{*}$
}

\author{
Tungíase sob dermatoscopia: exame in vivo e ex vivo da infestação cutânea pela \\ Tunga penetrans
}

\author{
Paulo Ricardo Criado ${ }^{1}$ \\ Vitor Manoel Silva dos Reis ${ }^{3}$
}

\author{
Gilles Landman² \\ Walter Belda Junior ${ }^{4}$
}

\begin{abstract}
The female flea Tunga penetrans is responsible for a cutaneous parasitosis known as Tungiasis. We report the clinical case of a 12 year-old Caucasian boy who sought treatment in a dermatological private office due to a painful lesion in the plantar area and whose dermoscopic examination, without skin contact, allowed the visualization of parasite's movement inside the skin. The diagnosis of tungiasis is clinical, but it can be aided by in vivo and ex vivo dermoscopic examination of the lesion.
\end{abstract}

Keywords: Communicable diseases; Dermoscopy; Ectoparasitic infestations; Siphonaptera

Resumo: A fêmea da pulga Tunga penetrans é responsável pela dermatose ectoparasitária denominada Tungíase. Relatamos o caso clínico de um adolescente branco de 12 anos de idade, o qual procurou atendimento em consultório dermatológico devido à lesão dolorosa na planta e cujo exame dermatoscópico sem contato com a pele permitiu visualizar o movimento do parasita dentro da pele. O diagnóstico da tungíase é clínico, porém pode ser auxiliado pelo exame dermatoscópico in vivo e ex vivo da lesão.

Palavras-chave: Dermoscopia; Doenças transmissíveis; Ectoparasitoses; Sifonápteros

The female flea Tunga penetrans is responsible for a cutaneous parasitosis known as Tungiasis. ${ }^{1}$ This small; one-millimeter long flea is endemic in countries of Latin America, Caribbean and sub-Saharan Africa. ${ }^{1,2}$ It may evolve with complications, such as secondary infections, lymphedema, bone exposing ulcerations, gangrene and tetanus. ${ }^{1}$ The parasite lives in dry soil, so that it can, especially during drought seasons, disperse in the ambient and penetrate the skin of the hosts (feline, swine and rodent), where it produces thousands of eggs whilst feeding on blood., The diagnosis of tungiasis is clinical, but it can, however be aided by in vivo and ex vivo dermoscopic examinations as described in the following case. ${ }^{3,4}$

Received on 17.08.2012.

Approved by the Advisory Board and accepted for publication on 24.10.2012.

* Work performed at Alergoskin Alergia e Dermatologia SS Ltda - São Paulo (SP), Brazil

Conflict of interest: None

Financial funding: None

MD, PhD in Dermatology at the University of São Paulo Medical School (FMUSP) - Member of the Dermatology Department at the University of São Paulo Medical School Clinics Hospital (HC-FMUSP) - São Paulo (SP), Brazil.

MD, PhD, Full Professor of Pathology at the Federal University of São Paulo (UNIFESP) - São Paulo (SP), Brazil.

MD, Full Professor at the University of São Paulo Medical School (FMUSP) - Dermatologist at the Dermatology Department at the University of São Paulo Medical School Clinics Hospital (HC-FMUSP) - São Paulo (SP), Brazil.

MD, PhD, Full Professor in Dermatology at the University of São Paulo Medical School (FMUSP) and the Campinas State University Medical School (UNICAMP) - Associated Professor at the Dermatology Department at the University of São Paulo Medical School (FMUSP) - São Paulo (SP), Brazil. 
A 12 year-old male patient reported since two weeks before, the presence of a painful lesion on the left plantar area. There was a history of traveling to the rural area in the countryside of São Paulo State. The clinical exam showed a $0.5 \mathrm{~cm}$ papule, yellowishwhite, with a black dot in its center (Figures 1A and 1B). With the aid of the dermatoscope (DermLite DL3, 3Gen, EUA), and without any skin contact we could observe a white halo, with bluish-gray areas and one central orifice containing a light-brown structure

Video available online at
http://www.anaisdedermatologia.org.br/
Video description
Observe the movement of the parasite's body (bluish-gray
areas) amidst the white halo.
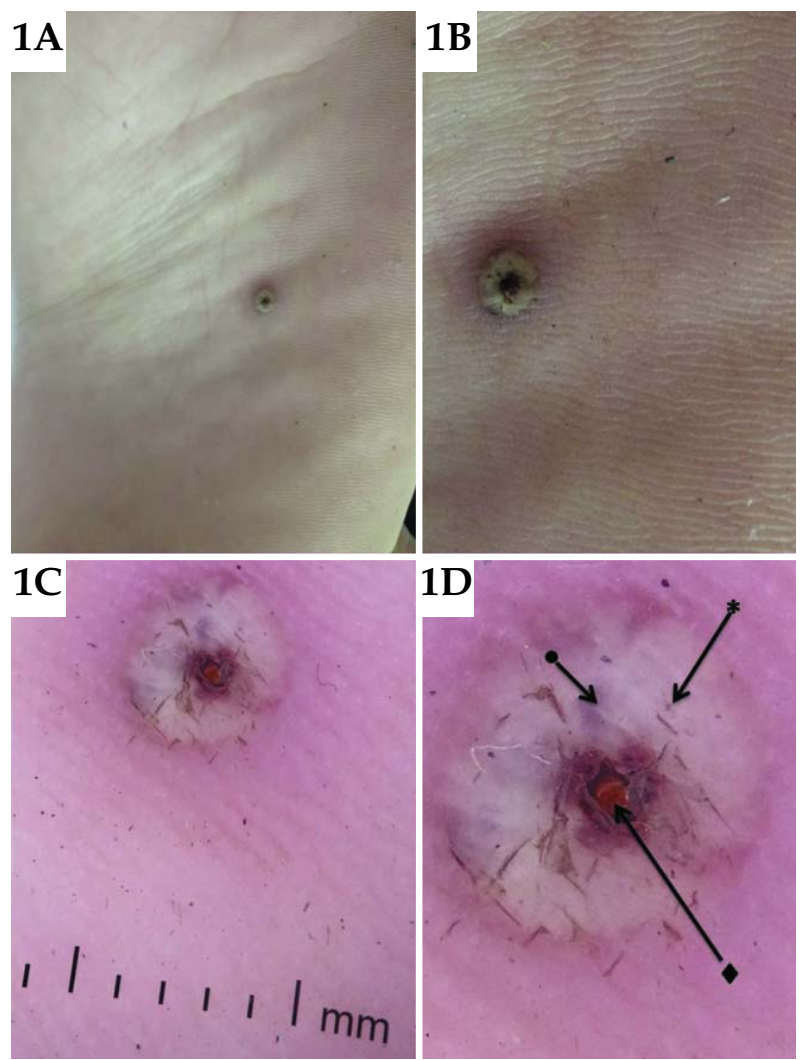

Figure 1: A - Yellowish-white plantar papule with a central black dot 1B: Figure 1A seen in greater detail. 1C: In vivo dermoscopy performed without skin contact showing a white halo with a central orifice containing a light-brown structure (original augmentation 10x). 1D: Figure 1C seen in greater detail, showing bluish-grey areas (likely corresponding to the parasite's exoskeleton or his gut) (-), White halo (corresponding to the parasite's dilated abdomen containing the eggs) (*) Light-brown structure appearing in the center of the orifice (posterior segment of the parasite) (
(Figures 1C and 1D). It was possible to observe movements on the bluish-gray areas inside the white halo (see video). We proceeded with the saucerization of the lesion, followed by hemostasis by fulguration.

The specimen was placed in a $4 \%$ formol solution and in the ex vivo observation it was possible to note the white ventral helical structures ("whitish chains"), as described initially by Bakos (Figures 2A and 2B) 5-8 The material was sent to histopathological analysis (Figures 2C and 2D).
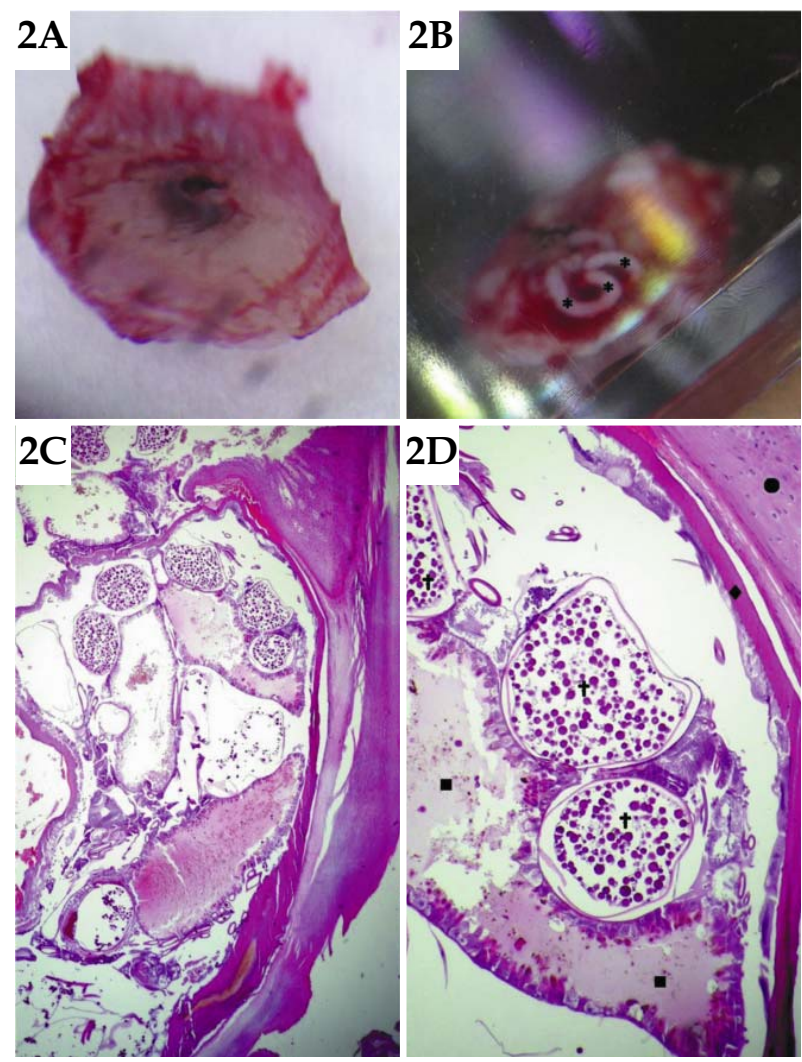

Figure 2A: Aspect of the saucerized lesion, embed in formol, the external portion of the lesion is seen through the dermatoscope. 2B: Ventral portion of the specimen, where oval structures corresponding to the eggs can be seen through the dermatoscope (*) (original augmentation 10x). 2C: Histopathological examination of the excised skin showing the parasite, the host's skin exhibiting compact hyperkeratosis and just below the epidermis, the parasite's body involved by a chitin structure (HE, 100x). 2D: Figure 2C seen in greater detail where it can be observed: the patient's straighten epidermis $(\bullet)$, the parasite's chitin exoskeleton $(\bullet)$, the flea's intestinal lumen (घ) the eggs inside the abdomen ( $\boldsymbol{(})$ 


\section{REFERENCES}

1. Heukelbach J, Sahebali S, Van Marck E, Sabóia Moura RC, Feldmeier H. An unusual case of ectopic tungiasis with pseudoepitheliomatous hyperplasia. Braz J Infect Dis. 2004;8:465-8.

2. Yotsu RR, Tamaki T, Ujiie M, Takeshita N, Kanagawa S, Kudo K, et al. Imported tungiasis in a Japanese student returning from East Africa. J Dermatol. 2011;38:185-9.

3. Vallarelli AFA, de Souza EM. Disseminated tungiasis. An Bras Dermatol. 2011;86:1027-8.

4. Dunn R, Asher R, Bowling J. Dermoscopy: ex vivo visualization of fleas head and bag of eggs confirm the diagnosis of Tungiasis. Australas $\mathrm{J}$ Dermatol. 2012;53:120-2

5. Bauer J, Forschner A, Garbe C, Röcken M. Dermoscopy of tungiasis. Arch Dermatol. 2004;140:761-3.

6. Di Stefani A, Rudolph CM, Hofmann-Wellenhof R, Müllegger RR. An additional dermoscopic feature of tungiasis. Arch Dermatol. 2005;141:1045-6.

7. Bakos RM, Bakos L. 'Whitish chains': a remarkable in vivo dermoscopic finding of tungiasis. Br J Dermatol. 2008:159:991-2.

8. Cabrera R, Daza F. Dermoscopy in the diagnosis of tungiasis. $\mathrm{Br} \mathrm{J}$ Dermatol. 2009;160:1136-7.

\section{MAILING ADDRESS:}

Paulo Ricardo Criado

Rua Carneiro Leão 33 - Vila Scarpelli

09050-430 - Santo André - SP

Brazil

E-mail: prcriado@uol.com.br

How to cite this article: Criado PR, Landman G, Reis VMS, Belda W Jr. Tungiasis under dermoscopy: in vivo and $e x$ vivo examination of the cutaneous infestation due to Tunga penetrans. An Bras Dermatol. 2013;88(4):649-51. 